\title{
Construction of Information Integration System for RFID-based Urban Intelligent Building
}

\author{
Wen HUANG \\ Wuhan Business University, 430050Wuhan, China
}

\begin{abstract}
Under the background of sustainable development, urban intelligent building is the inevitable direction of building development. This paper has analyzed the current situation of urban intelligent building in China, and expounded the application target of urban intelligent building based on Radio Frequency Identification (RFID) in the perspective of sustainable development.In the meantime,this paper has also made a profound analysis of the SWOT of RFID-based urban intelligent building, and puts forward a model framework, relevant key technology and construction mechanism for constructiment, thus improving the construction efficiency of the intelligent building for controlling the the component information more accurately, helping to optimize the industrial structure and improve the supervision ability of the intelligent building, and ultimately finding the effective way to realize the value of the sustainable development of the urban intelligent building.
\end{abstract}

\section{Introduction}

With the deepening of the sustainable development concept, intelligent building has become the goal of the urban construction industry. Intelligent building requires the integration of the whole life cycle supply chain in the construction process, but because of the lack of core automation technology, the data of the members of the supply chain are difficult to be integrated and unanimous, and thus the difficulty of integration is increased. At present, RFID (Radio Frequency Identification) has been widely used in many fields of automation management, such as industry and commerce. However, RFID is rarely used in the construction industry. The main reason is that the environment of the construction site is bad. Especially the information integration system of the RFID-based urban intelligent building does not have a complete theoretical system or implementation standard, which is unable to improve some management problems in the transportation and storage of urban intelligent building components, project progress control, and the information transmission in various stages of the construction life cycle. Therefore, such management problems have become key factors restricting the sustainable development of urban intelligent buildings. In order to solve these problems, we need to make a detailed research on the present situation of urban intelligent building in China, the application target, SWOT analysis and construction of the information integration system of RFID-based urban intelligent building. Through the research, a set of reasonable model framework is formed as well as relevant key technology and construction mechanism of the information integration system of RFID-based urban intelligent building, and the corresponding standards are also formed.

\section{Present situation of urban intelligent building in China}

China's intelligent building has been developing for more than 10 years since it started in the 1990s. People were unfamiliar with intelligent buildings. Now, the intelligent system, like fire fighting and hydro power, is an indispensable thought change in large buildings, commercial buildings, all kinds of public buildings and even residential areas. On this basis, the intelligent building gradually goes from the simple emphasis on intelligence and blind control technology towards the expected goal of strengthening intelligent technology and improving building function based on practical needs.

At present, the development of intelligent building in China (including western cities) has entered into a relatively mature stage of concept, market and technology. There are more than 2000 integrators in the field of intelligent building in China, and the total amount of intelligent engineering accounts for almost half of the world. But higher-level intelligent buildings are mostly concentrated in big public buildings (including office buildings) and commercial buildings; the intelligent degree of residential buildings is low, and these buildings have not reached the full range of popularization in intelligence. Especially in the process of constructing intelligent buildings, the standard is too high, which results in unbalanced development of regional structure and scale in China. For example, 
Beijing, Shanghai, Guangzhou, Shenzhen, Tianjin and Chongqing have taken the lead in entering the intelligent building, and other cities, such as Nanjing, Hangzhou, Shenyang, and Wuhan, are also advancing to the intelligent building. The western areas are late in the development of intelligent building in comparison with the developed areas in China. However, although the west is lagging behind, its starting point is high. Therefore, Chengdu, Chongqing and Xi'an are becoming the centers of higher education in China. At present, most of the construction intelligent projects in Shaanxi and Sichuan are undertaken by local integrators, and extend their business scope to adjacent areas of Sichuan and other provinces and cities in Northwest China. Building intelligent projects in Yinchuan, Xining and Guangxi are mostly contracted by external integrated companies.

\section{Application goal of RFID-based urban development from the perspective of sustainable development}

Architecture provides a relatively isolated space from nature. After the use of building technology, especially after the combination of high technology and architecture, it is bound to have new requirements for this space, i.e. the application goal of intelligent building technology must conform to people's needs of life and work, and the internal and external environment of the building should be a sustainable development space, and can play a certain role in disaster prevention. The main functions of the intelligent building include the comfortability of the user, the flexibility of the reorganization, the adaptability of the engineering, the energy saving of the system, the sustainability of the environmental protection, and the ability to greatly improve the handling of emergencies. At present, a very important goal of intelligent building is to save energy. The building energy saving mentioned in the white paper on China's Energy Status and Policy is one of the ten key points. Intelligent buildings have some close relationship with the following energy-saving measures: improving the energy saving of power and the efficiency of energy system, accelerating the application of high efficiency electrical appliances, green lighting, and so on.

The above energy-saving measures are manifested in two aspects: one is power and air conditioning, the other is lighting.Using the intelligent system to transform the air conditioning and power is not only improving the hardware itself, but also the operation mode. The operation mode in accordance with the energy saving requirement is actually managed through the form of software, which is embodied in the automation system of the building. And there are many ways to achieve energy saving in lighting, such as the efficient and reasonable mode of energy saving according to its own light source, which includes different environmental conditions, different control equipment, e.g. "intelligent lighting". A building automation system with perfect performance can achieve the goal of saving 20\%-30\% energy after energy saving control on air conditioning, power and lighting.

\section{SWOT analysis of urban intelligent building based on RFID}

\subsection{SWOT analysis}

Strength(S): (1) Colleges and universities and industry boast some higher- education civil engineering technical personnel who are engaged in research and development and practice work, and relevant material laboratories where researchers can be engaged in the experimental research of the RFID urban intelligent building industry application. (2) In addition to special construction projects, Chinese people are mature and experienced in the process of planning, design and construction of the general construction projects, and the upstream and downstream industries are quite complete. (3) Government departments actively promote the application of RFID in the public fields, and establish RFID promotion offices.

Weakness(W): (1) Because of industrial characteristics, architectural engineering is lack of RFID cross-domain motors, information, materials and professional personnel in other fields, resulting in the limitation on cross-domain RFID-related software and hardware facility and equipment research and development. (2) It is not easy to promote the development and application of industrial innovative technology by the non-governmental sector due to the lack of research and development functions and incentives. (3) Lack of relevant regulations, norms and standards on RFID in China results in the problem of impelling enforcement.

Opportunity (O): (1) Internationally, the related applications and research of RFID are actively promoting in various industries, resulting in a trend, and China's construction industry needs to respond actively. (2) There are many kinds and large quantities of materials needed in the urban intelligent building industry. RFID has been gradually developed in material and logistics management and control, and can be promoted to the vast building material market. (3) In recent years, other domestic industries have actively invested in the application of RFID and related software and hardware manufacturing and research, and much attention will be paid to the promotion and development of RFID in the future. (4) The application of RFID in Wal-Mart has been initially successful. With the gradual expansion of the amount of use, the low price RFID label will be available. It is foreseeable that it will be widely used in all walks of life to create additional value of goods and enhance the competitiveness of various industries.

Threat (T): (1) At present, the application of RFID has not reached scale economy. The high cost of its labels, software and hardware has impeded its development. (2) There are many related construction industries in China, but they are relatively small and have low willingness to invest in RFID. (3) Foreign 
RFID technology has long been widely used in various industries for many years. The introduction and development of RFID technology in China are relatively later than those in other countries, many technology patents are attained only in foreign countries, and the domestic development is restricted.

\subsection{Cross-strategy analysis of SWOT}

SO strategy: (1) On the one hand, relevant universities and civil engineering industry can integrate domestic talents and equipment, lead and promote the development and application of RFID in the urban intelligent building industry, helping to improve the efficiency of intelligent building engineering and reduce the cost of the related intelligent building. On the other hand, the cooperation with other RFID-related electronic industries in China should be taken into consideration to improve people's willingness to invest in the construction industry. (2) The government has listed the relevant application of RFID as a priority promotion plan and established the promotion office. Through the research results of urban intelligent building based on RFID, we can develop and work out the relevant standards of RFID in the urban intelligent building industry; through Wal-Mart's successful application experience and achievement in RFID, we can improve the investment in the urban intelligent building industry, finally achieving policy promotion, standard formulation, technology development and promotion of RFID application in urban intelligent building industry.

ST strategy: (1) Taking advantage of the domestic strength and the RFID-based urban intelligent building research results, we can integrate experts and scholars in different fields and domestic manufacturer resources, make co-operations on the application and soft and hard equipment research of RFID in the urban intelligent building industry, reduces the related cost, and promotes the development of the domestic urban intelligent construction industry. (2) The related innovative applications are available in China though many patents appear in foreign countries. Therefore, we can first list the research results of RFID-based urban intelligent building as a priority promotion plan through the application of RE-ID, then promote, guide and promote all these research results, and finally improve people's willingness of the domestic urban intelligent building.

WO strategy: (1) Through the research results of the application of RFID in intelligent building industry, relevant regulations, manuals and standards are formulated, and the successful application of RFID in Wal-Mart will be a major incentive to attract domestic investment in urban intelligent building industry. (2) The cross-domain integration among various fields is bound to become a trend, and so interdisciplinary professional talents should be integrated by RFID-based urban intelligent building, cooperate and develop the application and soft and hard equipment research of RFID in urban intelligent building industry.

WT strategy: (1) Because the urban intelligent building industry lacks RFID-based cross-field professional talents in other fields such as motors, information, and materials, the RFID-based urban intelligent building research should call for special talents in other fields to promote a link among industries, academic units and research institutions, integrate experts and scholars in different fields and domestic manufacturer resources, cooperate and develop the application and soft and hard equipment research of RFID in building industry, reduce the cost of related objects, and promote the development of the domestic urban intelligent building industry. (2) The government has listed the application of RFID as a priority promotion plan, but there is lack of relevant regulations, norms and standards. Therefore, it is necessary to formulate the relevant regulations, norms and standards through the research results of the RFID-based urban intelligent building, and use the research results as an example of the application of RFID in the urban intelligent building industry to advocate, guide and promote all these research results, finally increase the investment willingness of domestic urban intelligent building industry.

\section{Construction RFID-based urban intelligent building information integration system from the perspective of sustainable development}

According to the above analyses, in order to achieve the main application goal of RFID-based urban intelligent building, it is necessary to integrate all the equipment in the intelligent building, so it is of practical significance to construct the information integration system of the RFID-based urban intelligent building. In the life cycle of urban intelligent building, RFID identification technology is introduced, and an effective storage method is set up, i.e. setting up a RFID Tag on each component, so that the intelligent building components have the ability to automatically provide information, and effectively integrate the information needs of each stage, so as to complete the construction of the RFIDbased intelligent building demonstration house; and in the process of practical application, the correctness of the information link and the updating instantaneity of the component information are evaluated as the foundation for reanalyzing the construction safety when the needs of use change in the future, in order to more accurately control the information of the components, promote the construction efficiency of the intelligent building, facilitate the optimization of the intelligent building industry structure, and improve supervision ability.

The key technologies involved in this system are as follows:

Production: After the designs are confirmed, the component manufacturers can purchase materials and produce components according to the design requirements. After the components are produced, the RFID labels can be attached to them before consignment. The basic information on the required designs can be obtained by using the material management function of the RFID label, which can replace the traditional paper 
record method used by the original manufacturers when materials are fed or discharged, improving the efficiency of the material management and control, and saving the manpower needed for management and time.

Construction: The construction stage of the intelligent building follows the production stage. After the components leave the factory, they are transferred, stored, assembled and maintained. Then the information of each stage is integrated by the application of the RFID label, and the built engineering management system is used to monitor the assembly of the components.

Building energy saving: Firstly, in the building the active RFID is used to control the central air conditioning equipment to make the indoor temperature, humidity and ventilation achieve the purpose of comfort and energy saving, establish the urban intelligent building sensor network, and carry out the simulation and related application research and development of the building environment for the demonstration house. Secondly, the urban intelligent building sensor network application can be utilized to simulate the environment of RFID-based urban intelligent building in order to revise the design of the best energy-saving demonstration house, test the construction ways of environmental protection and energy saving in the demonstration house (e.g. testing solar induction boards, temperature regulators and automatic sun shading devices), and ultimately realize the application of RFID to the urban intelligent building energy saving materials to enhance the sustainability of integration.

The construction mechanism of RFID-based urban intelligent building information integration system should put forward in accordance with the features of the comfortability of the urban intelligent building, the flexibility of the re organization, the adaptability of the project, the energy saving of the system, the sustainability of the environmental protection, and the characteristics of the RFID-based function and management. In the process of implementing RFIDbased urban intelligent building information integration system engineering, it is vital to clear the construction target of the intelligent building, adhere to various standards and standards, develop many mature products and systems, further standardize the market, strictly manage system testing and acceptance, and realize the sustainable development of the urban intelligent building.

\section{Conclusions}

In the background of sustainable development, the urban intelligent building is the inevitable direction of building development. The information integration system of RFID-based urban intelligent building provides the periodical information needed in every stage. It can not only construct the mode of the application of RFID technology in urban intelligent building, but also apply this kind of mode to every stage of the actual urban intelligent building engineering life cycle, thus helping to enhance the efficiency of the overall planning, design, construction, operation, maintenance and management of the project, and the value of sustainable development of urban intelligent buildings can be truly realized.

\section{Acknowledgment}

Foundation Programs.Technological Innovation Team Programs for Distinguished Young and Middle-aged Scholars of Hubei Higher Education of China(T201829); Technological Innovation Programs of Wuhan Business University of China (2016KC04); 2018 Academic Team Programs of Wuhan Business University of China (2018TD003)

\section{References}

1. Z.W. Li. Computer Aided Design and Intelligent Building, 9,78(2011).

2. P.P. Wen . Enterprise Economy, 9,35(2012) .

3. N. Wang. Modern Architecture Electric, 10, 1 (2011).

4. L. C.Wang, Y. C. Lin, P. H.Lin. Advanced Engineering Informatics, 4, 377(2011).

5. J. Patrick, I. L. Sweeney. Wiley Publishing Inc, 205(2012).

6. B.Zhang, Y. H.Yao. Value Engineering, 113(2014).

7. Q. Zeng, Y. Ouyang. China Economic Publishing House, 165(2013).

8. F. Nakib . Conference on Technology \& Sustainability in the Built Environment, 479(2012). 